\title{
ÚNG DỤNG GIS TRONG CÔNG TÁC GIẢI PHÓNG MẠT BẰNG TUYẾN ĐƯỜNG VÀNH ĐAI 2 CỦA THÀNH PHỐ HÀ NỘI (ĐOẠN VĨNH TUY - CHỌ MƠ - NGÃ TU’ VỌNG)
}

\author{
PHẠM LÊ TUẤN(1), HÀ QUỐC VƯƠNG(2), NGUYẼ̃N XUÂN LINH ${ }^{(1)}$, \\ LÊ PHƯƠNG THÚY ${ }^{(1)}$, BÙI NGỌC TÚ(1), TRÀ̀N QUỐC BİNH ${ }^{(1)}$ \\ ${ }^{(1)}$ Khoa Địa lý, Truòng Đại họ Khoa hoc Tụ nhiên, ĐHQGHN \\ (2)Viện Nghiên cưu Quản lý Đất đai, Tổng cuc Quản lý Đất đai
}

\section{Tóm tắt:}

Trong các dự án phát triển giao thông đô thị tại Hà Nội, công tác bồi thường giải phóng mặt bằng (GPMB) luôn nhận được sụ quan tâm của xã hội và các co quan quản lý. Việc lập phương án bồi thuờng, giải phóng mặt bằng có đầy đủ thông tin, đảm bảo độ chính xác, đáp ứng nhu cầu của các bên liên quan luôn là vấn đề được quan tâm. Trong nghiên cứu này, các tác giả đã nghiên cúu và ưng dụng GIS để hố trọ công tác bồi thương, giải phóng mặt bằng cho dụ án xây dưngtuyến đường Vành đai 2, đoạn Vĩnh Tuy - Chọ Mo - Ngã Tu Vọng của thành phố Hà Nội. Kết quả đã thành lập được co sở dĩ liệu đất đai cho tuyến đường Vành đai 2, trên co sở đó tính toán diện tích trong và ngoài chỉ giới đường đỏ, tính giá bồi thường về đất và nhà cho các thửa đất trong phạm vi dư án và tạo kênh thông tin về quy hoạch của dụ án trên mạng internet.

\section{Mỏ̉ đầu}

Ngày nay, cùng với sự phát triển của khoa học công nghệ, việc ứng dụng hệ thống thông tin địa lý (GIS) vào các lĩnh vực của đời sống ngày càng nhiều. Một trong số đó phải kể đến là ứng dụng GIS trong công tác quản lý đất đai nói chung và trong công tác giải phóng mặt bằng nói riêng. Một số ứng dụng thực tế của GIS có thể kể đến như: Manonmani và cộng sự (2012) đã ứng dụng công nghệ GIS và các kỹ thuật xử lý ảnh nhằm quy hoạch chi tiết thành phố Karaikal Ấn Độ và lập bản đồ thể hiện các tiện ích sẵn có ở thành phố này [7]. WangXin (2012) đã thiết kế một hệ thống thông tin quy hoạch đô thị trên cơ sở ứng dụng công nghệ GIS. Thiết kế dành cho loại đô thị vừa và nhỏ này sẽ giúp cho các chương trình xây dựng khả thi hơn [9]. Syed và Sohieb (2014) đã chỉ ra hiệu quả của hệ thống GIS quản lý hạ tầng đô thị tại dự án triển khai ở Kulgaon-Badlapur (Ấn Độ). Hệ thống này đã rút ngắn luồng thông tin giữa chính quyền đô thị với người dân và các bộ phận liên quan, tăng cường một cách rõ nét sự phối hợp giữa các đơn vị tham gia quản lý hạ tầng đô thị [8].

Việc ứng dụng GIS trong quản lý đô thị mang lại nhiều lợi ích nhưng việc triển khai chúng cũng gặp nhiều khó khăn. Kohsaka (2001) đã chỉ ra rằng nhiều đô thị ở Nhật Bản đã chi những khoản kinh phí lớn nhưng kết quả đạt được thì khá khiêm tốn, thậm chí có những hệ thống được sử dụng rất hạn chế ngay cả bởi chính quyền. Bên cạnh những khó khăn về kỹ thuật, một trong những nguyên nhân dẫn đến thất bại của nhiều hệ thống GIS là chưa bám sát vào những hoạt động thường ngày của đô thị, chưa có nhiều thông tin thiết thực cho người dân [6].

Ở nước ta, công tác bồi thường GPMB của các dự án phát triển giao thông đô thị đang là vấn đề cấp bách đối với Nhà nước và các cơ quan chức năng trong công cuộc xây dựng và phát triển đất nước. Công tác bồi thường GPMB phải trải qua nhiều giai đoạn, đa phần được thực hiện riêng rẽ, không có sự thống nhất và đồng bộ giữa các dự án với nhau, việc tính toán khối lượng công việc được làm thủ công cho từng thửa đất. Trong đó, các dự án nghiên cứu ứng dụng GIS để

Ngày nhận bài: 27/3/2018, ngày chuyển phản biện: 30/3/2018, ngày chấp nhận phản biện: 27/4/2018, ngày chấp nhận đăng: 10/5/2018 
xây dựng CSDL đất đai đang được Nhà nước quan tâm, đầu tư, triển khai thực hiện như xây dựng CSDL Địa chính, CSDL giá đất, CSDL quy hoạch $[1,2,3,4]$. Như vậy, việc ứng dụng GIS để xây dựng CSDL đất đai phục vụ công tác giải phóng mặt bằng thuộc các dự án giao thông đô thị và giải quyết một số bài toán trong quá trình giải phóng mặt bằng là vấn đề mang tính cấp thiết, cần được nghiên cứu và đưa vào triển khai thực tế.

\section{Khu vực nghiên cứu và dữ liệu}

Đường Vành đai 2 là tuyến giao thông nội đô khép kín của Hà Nội, có tổng chiều dài là 43,6 $\mathrm{km}$, đi qua địa bàn nhiều quận theo các tuyến đường: cầu Vĩnh Tuy - đường Minh Khai - Ngã Tư Vọng - Ngã Tư Sở - Cầu Giấy - cầu Nhật Tân - cầu Đông Trù - cầu chui Gia Lâm - cầu Vĩnh Tuy.Hiện nay, việc mở rộng tuyến đường Vành đai 2 theo quy hoạch của thành phố Hà Nội đang được triển khai, đoạn từ cầu Vĩnh Tuy đến Ngã Tư Vọng đang trong giai đoạn làm hồ sơ GPMB, đoạn từ cầu Vĩnh Tuy đến cầu Mai Động đã hoàn thành điều tra khảo sát, phê duyệt phương án bồi thường đối với đa số tổ chức, hộ dân thực diện GPMB[5]. (Xem hình 1)

Các tài liệu bản đồ phục vụ dự án xây dựng tuyến đường Vành đai 2 được thu thập và sử dụng bao gồm: Bản đồ hiện trạng tỷ lệ 1/500 lập tháng 4/2011, bản vẽ "Chỉ giới đường đỏ" tuyến đường Vành đai 2 (Phần dưới đất) đoạn Vĩnh Tuy - Chợ Mơ - Ngã Tư Vọng ở tỷ lệ 1/500 lập và hoàn thành năm 2011, bản đồ trích đo địa chính tỷ lệ 1/500 lập năm 2013 và 2017.

Ngoài dữ liệu bản đồ, các văn bản, quyết định có liên quan đến tuyến đường Vành đai 2 được thu thập và sử dụng bao gồm: Quyết định số 368/QĐ-UBND ngày 21/01/2016 của UBND thành phố Hà Nội về hệ số điều chỉnh, giá đất làm căn cứ bồi thường, hỗ trợ giải phóng mặt bằng của dự án, Quyết định số 96/2014/QĐUBND ngày 29/12/2014 của UBND thành phố Hà Nội về khung giá đất giai đoạn 2015-2019.

\section{Xây dựng CSDL đất đai phục vụ giải phóng mặt bằng tuyến đường vành đai 2}

\subsection{Cấu trúc, mô hình CSDL đất đai}

Để xây dựng CSDL đất đai, các lớp dữ liệu không gian đất đai và dữ liệu thuộc tính đất đai phải được chuẩn hóa về cấu trúc và kiểu thông tin theo Thông tư số 75/2015/TT-BTNMT. Mô hình CSDL đất đai phục vụ GPMB tuyến đường Vành đai 2 được thể hiện tại hình 2. Do là một CSDL đất đai đặc thù, phục vụ trực tiếp cho công tác bồi thường, giải phóng mặt bằng nên nội dung thông tin đã được giản lược so với một

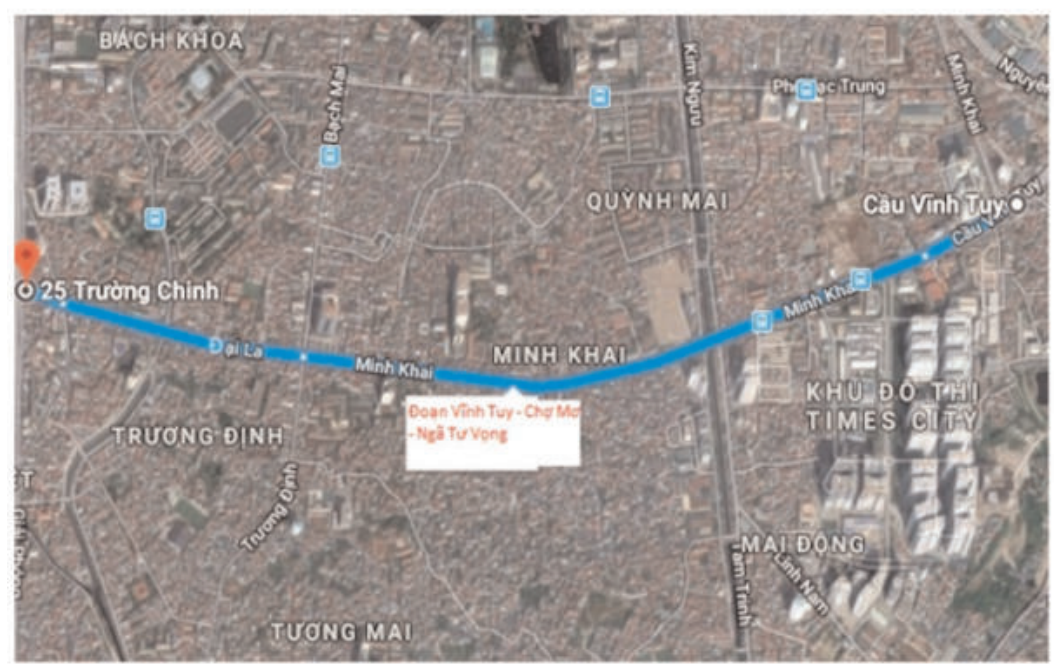

Hình 1: Đoạn Vĩnh Tuy - Chợ Mo - Ngã Tu Vọng của tuyến đường Vành đai 2 
CSDL đất đai tổng quát, phục vụ cho nhiều mục đích khác nhau. (Xem hình 2)

CSDL đất đai tuyến đường Vành đai 2 được xây dựng gồm các lớp dữ liệu:

- Thua_dat: Lưu trữ các thông tin liên quan đến thửa đất như: chủ sử dụng, diện tích, số hiệu thửa, mã vị trí,...

- Diem_khong_che: Lưu trữ thông tin về các điểm khống chế.

- Giao_thong: Lưu trữ các thông tin liên quan đến giao thông như: mã vị trí, tên đường.

- Biengioi_diagioi: Lưu trữ các thông tin liên quan đến đơn vị hành chính như: ranh giới xã (phường), tên phường, diện tích.

- Quy_hoach: Lưu trũ̃ các thông tin quy hoạch sử dụng đấtt như: vị trí quy hoạch, mục đích, chỉ giới đường đỏ, diện tích,...

- Y_kien_phan_hoi: Lưu trữ các thông tin ý kiến phản hồi của người dân và thông tin trả lời, giải đáp của ban bồi thường GPMB.

\subsection{Xây dụng CSDL đất đai tuyến đường} vành đai 2 (dọ̣n Vĩnh Tuy-Chọ Mó-Ngã Tu Vong)

Để giúp công tác GPMB của các dự án phát triển giao thông đô thị được triển khai nhanh chóng, đảm bảo độ chính xác và công khai minh bạch thông tin đến người dân thì việc xây dựng CSDL đất đai là khâu quan trọng, cần phải thực hiện trước tiên.

Từ dữ liệu bản đồ thu thập được, các tác giả đã thực hiện chuẩn hóa bản đồ bằng phần mềm Microstation. Sử dụng các công cụ của Microstation để đưa các đối tượng về các lớp dữ liệu theo đúng quy định, kiểm tra các lỗi về quan hệ không gian (topology), sửa lỗi tự động, tạo vùng, đánh số thửa, vẽ nhãn thửa, kiểm tra thông tin thuộc tính của các thửa đất để đảm bảo mỗi thửa đất đều chứa đầy đủ thông tin thuộc tính bao gồm số hiệu thửa, loại đất, diện tích, chủ sử dụng, địa chỉ.

Sau khi được chuẩn hóa trong phần mềm Microstation, dữ liệu được chuyển đổi vào các Feature Class của phần mềm ArcGIS ở định dạng Polyline, Polygon, Point, Annotation để tiếp tục chuẩn hóa. Tiến hành tách chiết các lớp

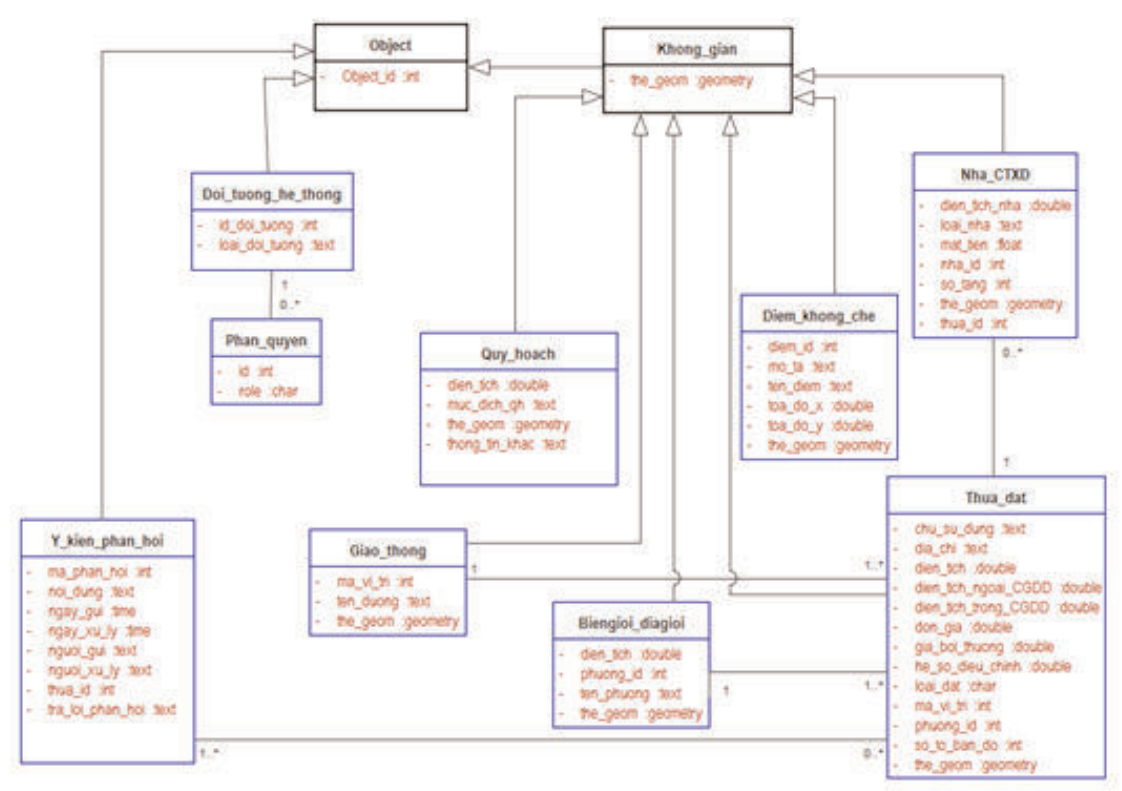

Hình 2: Mô hình CSDL đất đai tuyến đưòng Vành đai 2 
thông tin bằng cách lệnh truy vấn theo trường thuộc tính của đối tượng và chuẩn hóa quan hệ không gian cho lớp dữ liệu thửa đất.

Các nhóm dữ liệu được xây dựng để phục vụ công tác GPMB của đoạn Vĩnh Tuy - Chợ Mơ Ngã Tư bao gồm: Nhóm dữ liệu điểm khống chế đo đạc, nhóm dữ liệu biên giới, địa giới, nhóm lớp dữ liệu địa chính, nhóm lớp quy hoạch, kế hoạch sử dụng đất, dữ liệu thuộc tính của thửa đất, dữ liệu giá đất.

\section{Giải quyết một số bài toán của công tác} bồi thường, giải phóng mặt bằng tuyến đường Vành đai 2

Trong phần tiếp theo của nghiên cứu, các tác giả đã sử dụng CSDL đất đai thành lập được cùng với các chức năng phân tích, hiển thị dữ liệu của GIS để giải quyết một số bài toán thiết thực của công tác GPMB: xác định phạm vi thu hồi đất đai, tính giá bồi thường, phổ biến thông tin liên quan đến đất đai của dự án và tiếp nhận ý kiến phản hồi của các bên liên quan.

\subsection{Xác định diện tích trong, ngoài chỉ giới} đường đỏ phục vụ công tác giải phóng mặt bằng

Trong các dự án cần GPMB, việc xác định diện tích trong, ngoài chỉ giới đường đỏ (CGĐĐ) luôn được các hộ dân trong vùng quy hoạch và các cơ quan chức năng đặc biệt quan tâm, Người dân muốn biết phần diện tích còn lại hoặc mất đi của mình sau khi GPMB để lên kế hoạch xây dựng nhà cửa hoặc di chuyển đến nơi ở mới. Cơ quan chức năng cần biết phần diện tích nằm trong phạm vi dự án để xây dựng phương án bồi thường GPMB.
Thực hiện chồng xếp 2 lớp dữ liệu thửa đất và lớp vùng quy hoạch, ta sẽ thu được lớp Thua_dat_DT_CGDD. Qua phân tích dữ liệu của lớp này, ta sẽ thấy có 3 trường hợp xảy ra như trong bảng 1 .

Các dữ liệu của lớp Thua_dat_DT_CGDD được chuyển đổi sang phần mềm Excel để lọc dữ liệu và gán giá trị diện tích trong, ngoài chỉ giới đường đỏ cho các thửa đất. Kết quả được như trên hình 3 .

\subsection{Tính giá bồi thường cho đất ở và nhà ở}

Sau khi xác định phần diện tích nằm trong phạm vi dự án như đã trình bày ở trên, có thể tính giá bồi thường cho các thửa đất và nhà ở thuộc phạm vi GPMB. Đây là công việc đòi hỏi độ chính xác cao vì liên quan trực tiếp đến quyền lợi của người dân, dễ làm xảy ra khúc mắc, khiếu nại.

\section{a. Tính giá bồi thường đất ở}

Lớp CSDL_Chuan được gán hệ số điều chỉnh theo Quyết định số 368/QĐ-UBND ngày 21/01/2016 của UBND thành phố Hà Nội để tính giá bồi thường về đất cho từng thửa đất:

Tiền bồi thường đất = Giá theo khung giá Nhà nước * Diện tích trong chi giới đường đỏ * hệ số điều chinh theo QĐ 368

\section{b. Tính giá bồi thường nhà ở trên đất}

Để tính được giá bồi thường nhà ở cho tất cả các thửa đất, ta cần xác định số lượng nhà nằm trong phạm vi GPMB của từng thửa đất, xác định loại nhà, số tầng và gán đơn giá phù hợp với từng loại nhà. Để xác định số lượng nhà, sử dụng công cự tìm kiếm theo không gian để xác định số lượng nhà nằm trong hoặc giao cắt với chỉ giới

Bảng 1: Các trương hợp quan hệ không gian giũa thửa đất và CGĐĐ

\begin{tabular}{|c|c|c|c|}
\hline Các trường hợp & $\begin{array}{c}\text { Giá trị trường ID lớp dữ liệu } \\
\text { thửa đất }\end{array}$ & $\begin{array}{c}\text { Giá trị trường ID lớp dữ liệu } \\
\text { vùng quy hoạch }\end{array}$ & Ghi chú \\
\hline CGĐĐ cắt qua & Trùng nhau & $\begin{array}{l}=1 \\
=-1\end{array}$ & $\begin{array}{l}\text { Nằm trong CGĐĐ } \\
\text { Nằm ngoài CGĐĐ }\end{array}$ \\
\hline Nằm trọn vẹn trong CGĐĐ & 1 số duy nhất & $=1$ & Nằm trong CGĐĐ \\
\hline Nằm ngoài CGĐĐ & 1 số duy nhất & $=-1$ & Nằm ngoài CGĐĐ \\
\hline
\end{tabular}


đường đỏ. Đơn giá bồi thường về nhà ở được lấy theo quy định hiện hành của UBND thành phố Hà Nội theo Quyết định số 06/2017/QĐ-UBND ngày $03 / 3 / 2017$ :

Tiền bồi thuờng nhà ở = Loại nhà * Số tầng * Đon giá * Diện tích

c. Tính tổng giá bồi thường cho tùng thưa đất

Tổng giá bồi thường cho từng thửa đất là mức giá mà mỗi hộ dân dự kiến nhận được khi Nhà nước thu hồi đất để thực hiện dự án. Mức giá này bằng tổng của giá bồi thường về đất ở cộng giá bồi thường về nhà ở và các tài sản khác gắn liền với đất (hình 4).

\subsection{Công bố thông tin quy hoạch của dự án và thu nhận phản hồi của người dân}

Hiện nay, trong công tác GPMB cho các dự án phát triển giao thông đô thị, việc công khai thông tin quy hoạch đến người dân chủ yếu được thực hiện bằng hình thức in bản đồ treo ở UBND phường, nhà văn hóa, tuyến đường có quy hoạch,... Công việc này gây khó khăn cho người dân trong việc tiếp cận thông tin mọi lúc, mọi nơi. Bên cạnh đó, với sự phát triển của cách mạng công nghệ, Internet đã trở nên phổ biến trong xã hội, đặc biệt là ở các khu vực đô thị. Do vậy, với mục tiêu công khai quy hoạch tuyến đường Vành đai 2, đoạn Vĩnh Tuy - Chợ Mơ Ngã Tư Vọng đến cho người dân, việc xây dựng một hệ thống thông tin hoạt động trên môi trường Internet là giải pháp hữu hiệu để tạo kênh trao đổi thông tin với người dân.

Hệ thống thông tin do các tác giả phát triển dựa trên nền tảng các phần mềm mã nguồn mở (PostgreSQL/PostGIS, MapServer, pMapper, Apache) và người sử dụng hệ thống có thể tiếp cận được thông tin qua hầu hết các thiết bị có kết

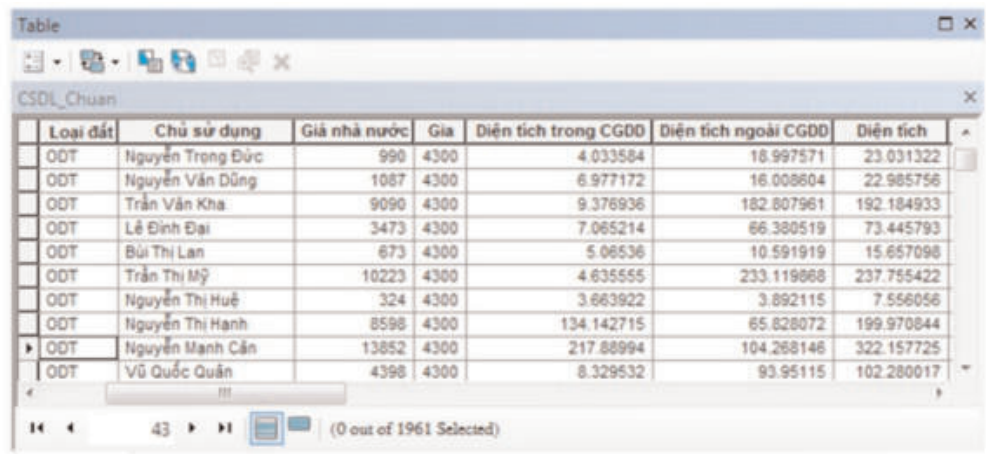

Hình 3: Kết quả tính diện tích trong, ngoài CGĐĐ

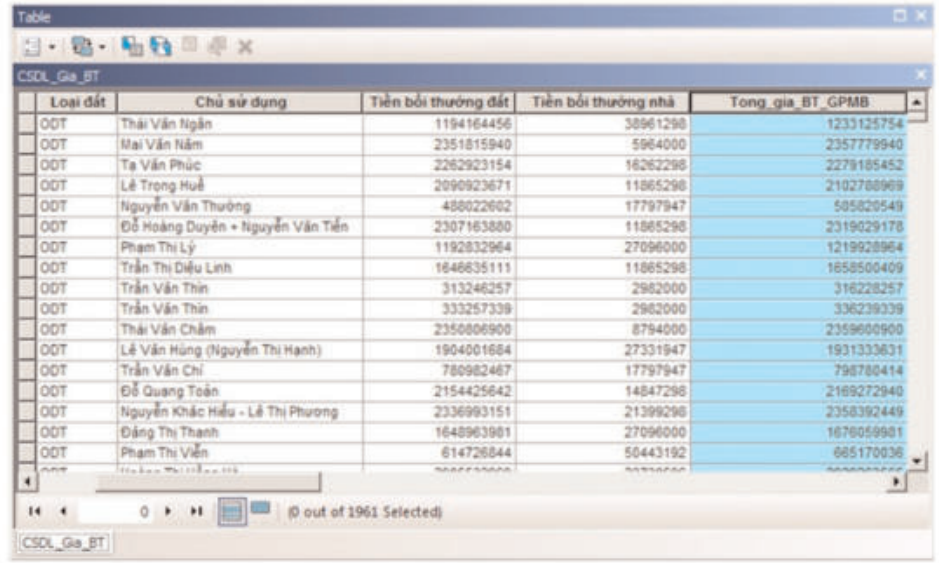

Hình 4: Kết quả tính bồi thường cho đất ở và nhà ở 
nối internet (máy tính, điện thoại thông minh, máy tính bảng,...), chỉ cần sử dụng một trình duyệt có sẵn như FireFox, Chrome, Internet Explorer,... Các chức năng của hệ thống được thể hiện bằng sơ đồ ca sử dụng trên hình 5 .

* Chức năng dành cho người sủ dụng đất

Người sử dụng có 2 chức năng chính là:

- Xem bản đồ quy hoạch tuyến đường Vành đai 2 và tra cứu thông tin thửa đất: Ngoài các chức năng cơ bản như phóng to, thu nhỏ, di chuyển để xem bản đồ chi tiết hơn, người sử dụng có thể truy vấn thông tin của thửa đất bằng cách chọn công cụ và đưa chuột vào thửa đất, hệ thống sẽ hiển thị thông tin của thửa đất đó ở góc dưới bên phải màn hình, trong đó có đầy đủ thông tin thuộc tính của thửa đất

- Gửi ý kiến phản hồi: Khi có kiến nghị hoặc ý kiến góp ý trong quá trình thực hiện công tác bồi thường GPMB của dự án đường Vành đai 2 như góp ý về các hình thức bồi thường GPMB, diện tích nằm trong chỉ giới đường đỏ, tiến độ triển khai GPMB,... người sử dụng đất sẽ gửi ý kiến phản hồi vào hệ thống. Nội dung phản hồi sẽ được hệ thống ghi nhận lại và gửi đến các cán bộ quản lý (hình 6). lý

* Chức năng nâng cao dành cho cán bộ quản

Đối với cán bộ quản lý, hệ thống thiết kế các chức năng nâng cao hơn để giúp cán bộ quản lý điều hành và sử dụng hệ thống một cách tốt nhất.

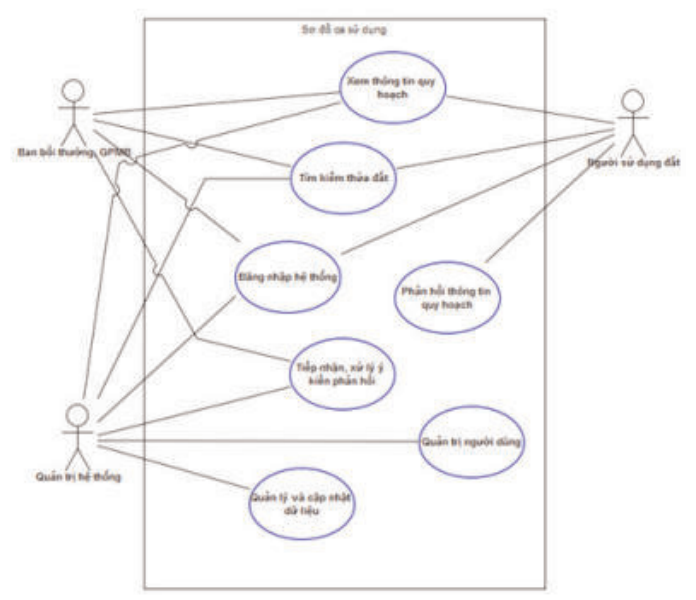

Hình 5: So đồ ca sử dụng của hệ thống thông tin tuyến đường Vành đai 2

- Chức năng quản trị người dùng: người quản trị hệ thống sẽ quản lý và kiểm soát các thành viên tham gia vào hệ thống cũng như phân quyền cho các nhóm thành viên.

- Chức năng tiếp nhận và xử lý các ý kiến phản hồi: Trên cơ sở tiếp nhận các ý kiến đóng ý của người dân và các bên liên quan, các cán bộ phụ trách của Ban bồi thường GPMB sẽ tiếp thu những đóng góp và trả lời những thắc mắc cũng người dân liên quan đến công tác bồi thường GPMB tuyến đường Vành đai 2 (hình 7).

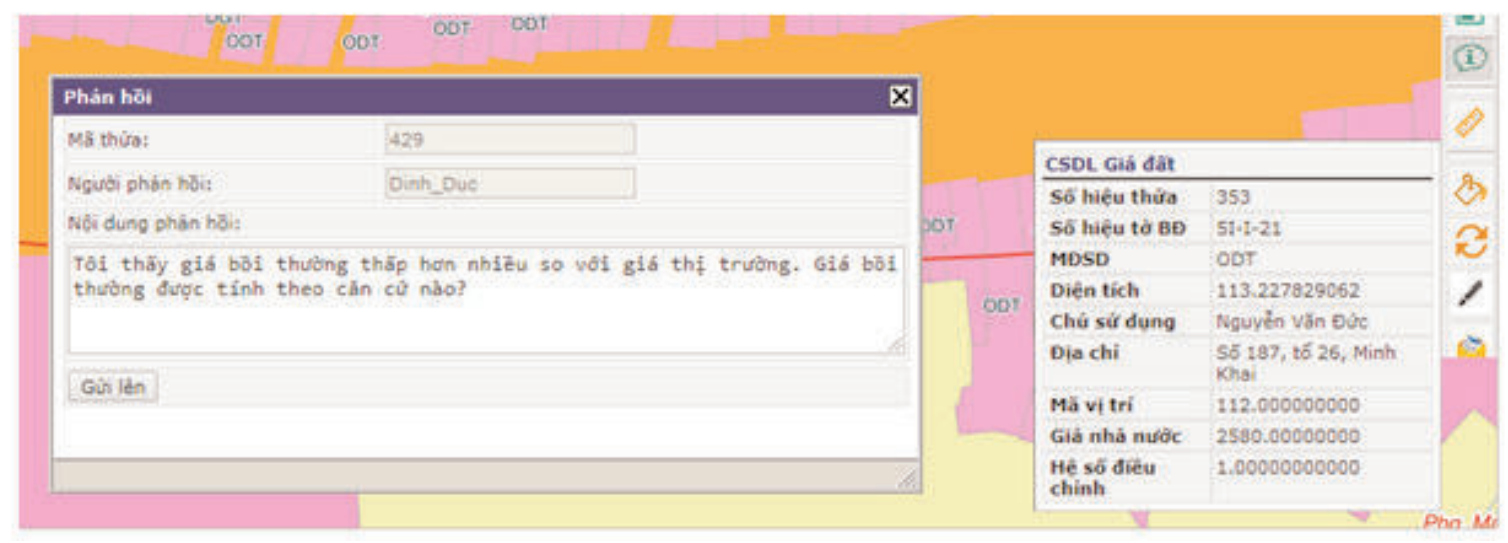

Hình 6: Các chức năng của người sủ dụng đất 


\section{Kết luận}

Nghiên cứu đã ứng dụng thành công công nghệ GIS để xây dựng CSDL đất đai đoạn Vĩnh Tuy - Chợ Mơ - Ngã Tư Vọng thuộc Dự án đường Vành đai 2 từ nguồn dữ liệu bản đồ thu thập được của dự án. Trên cơ sở CSDL đất đai được xây dựng, các tác giả đã giải quyết một số vấn đề thực tiễn trong công tác GPMB tại tuyến đường Vành đai 2 như xác định diện tích trong và ngoài chỉ giới đường đỏ, tính giá bồi thường về đất ở và nhà ở cho tất cả các thửa đất, công khai thông tin về dự án lên mạng Internet cho người dân và lấy ý kiến đóng góp của các bên liên quan. Các kết quả nghiên cứu góp phần khẳng định GIS là một công cụ hỗ trợ hiệu quả cho công tác quản lý đất đai và vì vậy, chính quyền thành phố Hà Nội nên chỉ đạo việc tăng cường ứng dụng GIS trong các dự án phát triển hạ tầng đô thị. $O$

\section{Tài liệu tham khảo}

[1]. Trần Quốc Bình (2010), Khả năng ưng dụng các phần mềm GIS mã nguồn mở trong xây dưng hệ thống thông tin đất đai, Hội nghị khoa học Địa lý Đông Nam Á, NXB Đại học Sư phạm.

[2]. Đoàn Quang Cương, Trần Văn Tuấn, Phạm Lê Tuấn (2017), Nghiên cứu xây dụng co sở dĩ liệu quy hoạch sư dụng đất huyện Đông Anh, thành phố Hà Nội, Kỷ yếu Hội thảo ứng dụng GIS toàn quốc 2017, tr. 467-475.

[3]. Lê Phương Thúy, Nguyễn Xuân Linh (2014), Nghiên cứu đề xuất mô hình cơ sở dũ liệu địa chính phục vu đăng ký đất đai trên co sở mô hình $L A D M$, Kỷ yếu Hội nghị Khoa học Địa lý lần thứ 8 , Trường Đại học Sư phạm TP. Hồ Chí Minh, 1-2/11/2014, tr. 790-797.

[4]. Phạm Anh Tuấn, Nguyễn Xuân Linh, Phạm Lê Tuấn, Phạm Sỹ Liêm, Bùi Thị Cẩm Ngọc (2014), Thực nghiệm xây dụng cơ sở dũ liệu giá đất ở đô thị trên co sở úng dụng kỹ thuật CAMA tại phưòng Hoàng Văn Thu, thành phố Bắc Giang, tỉnh Bắc Giang, Tạp chí Nông nghiệp và Phát triển Nông thôn, số 14, tr. 19-25.

[5]. UBND quận Hai Bà Trưng (2017), Công tác Giải phóng mặt bằng của quận Hai Bà Trung 2017- một năm nhiều dấu ấn, Địa chỉ truy cập: http://haibatrung.hanoi.gov.vn/quan-ly-do-thi1/-

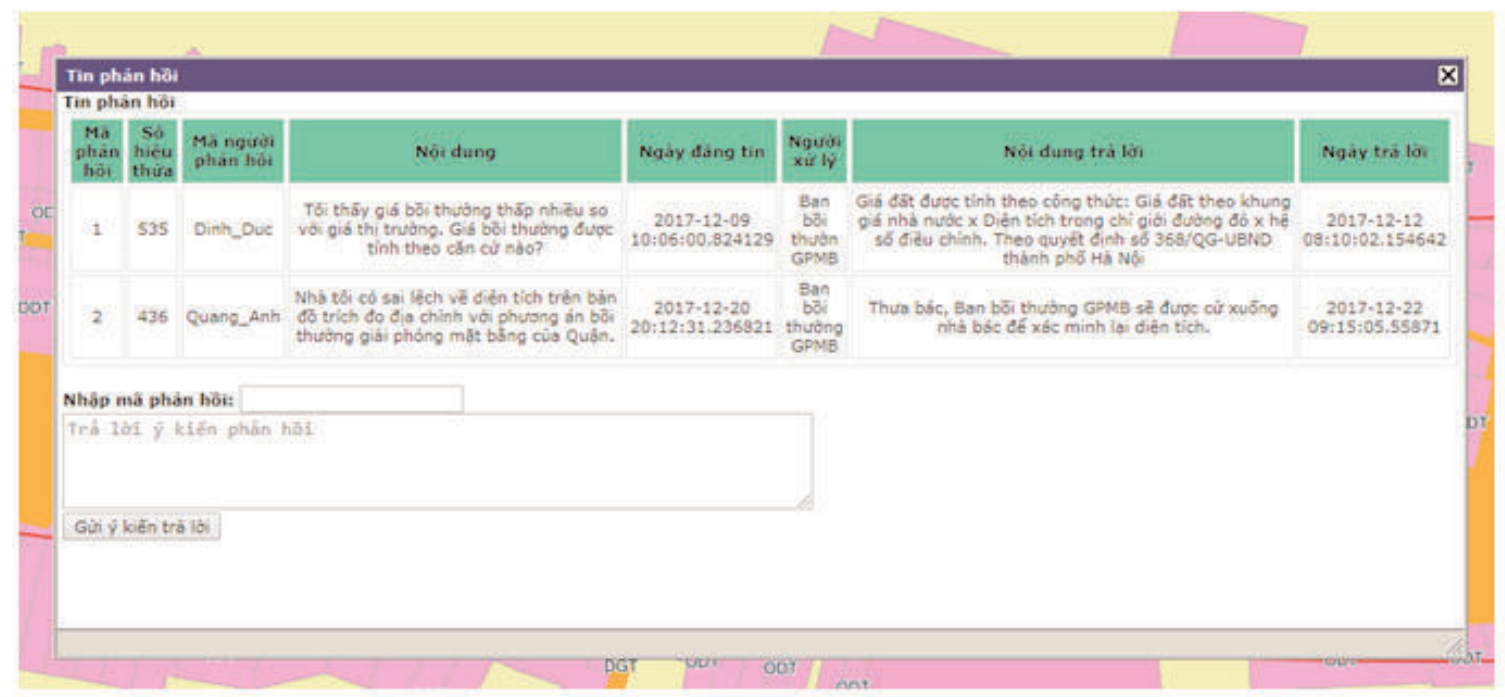

Hình 7: Chức năng quản lý phản hồi của cán bộ quản lý 
/view_content/2129627-cong-tac-giai-phongmat-bang-cua-quan-hai-ba-trung-2017-motnam-nhieu-dau-an.html.

[6]. Kohsaka H. (2001). Applications of GIS to urban planning and management: Problems facing Japanese local governments.GeoJournal, Vol.52(3), pp. 271-280.

[7]. ManonmaniR., PrabaharanS., VidhyaR., RamalingamM. (2012), Application of GIS in urban utility mapping using image processing techniques, Geo-spatial Information Science, 15
(4), 271-275.

[8]. Syed A.F. and Sohieb G. (2014). Application of Geographical Information System in Urban Management and Planning: A Case Study of Kulgaon-Badlapur, Dist-Thane, Maharashtra. International Journal of Advanced Remote Sensing and GIS, Vol.3(1), pp. 476-485.

[9]. Wang Xin (2012), Urban Planning and Management Information Systems Analysis and Design Based on GIS, Physics Procedia, 33, 1440-1445. 0

\section{Summary}

Research on the application of GIS in the site clearance in Ring Road 2 of Hanoi (Vinh Tuy - Cho Mo - Nga Tu Vong)

Pham Le Tuan, Nguyen Xuan Linh, Le Phuong Thuy, Bui Ngoc Tu, Tran Quoc Binh

Faculty of Geography Hanoi University of Science

Ha Quoc Vuong

Research Institute of Land Administration, General Department of Land Administration

In urban transport development projects in Hanoi, compensation and site clearance has always received the attention of the society and management agencies. It is always a matter of concern to make a plan for compensation and site clearance with sufficient information, ensuring accuracy and meeting the needs of stakeholders. In this study, the authors have researched and applied GIS to support the compensation and clearance work for the project of building Ring Road 2, Vinh Tuy - Cho Mo - Nga Tu Vong, Hanoi. The result has established a database management for the Ring Road 2, which calculates the area inside and outside the red line, calculates the compensation price for parcels and houses within the boundaries of project and create a land use planning information system on the internet. $\mathrm{O}$ 